\title{
Acceptability and effectiveness of helpline services: Perspectives of women in distress and service providers-Policy brief
}

\author{
K.G. Santhya \\ Population Council \\ Shireen J. Jejeebhoy
}

Follow this and additional works at: https://knowledgecommons.popcouncil.org/departments_sbsr-pgy

Part of the Demography, Population, and Ecology Commons, Family, Life Course, and Society Commons, International Public Health Commons, and the Women's Health Commons How does access to this work benefit you? Let us know!

\section{Recommended Citation}

Santhya, K.G. and Shireen J. Jejeebhoy. 2017. "Acceptability and effectiveness of helpline services:

Perspectives of women in distress and service providers," Policy brief. New Delhi: Population Council. 


\section{Acceptability and effectiveness of helpline services: Perspectives of women in distress and service providers}

\section{Introduction}

In India, not only is violence against women and girls (VAWG) widespread, but help seeking for domestic violence is limited, a situation that, in turn, reduces women's ability to prevent further violence. Furthermore, where help is sought, it is rarely sought from institutional sources. In Bihar, characterised by the highest prevalence of marital violence in the country, helplines for women who experience violence exist in almost every district; these helplines provide counselling services, including for couples seeking reconciliation of differences, and facilitate legal, medical and housing services for women in need. Notwithstanding the availability of these helplines, little is known about the perspectives and experiences of women who have used helpline services.

This brief describes, from the perspectives of women who sought services from the helpline, the range and perceived quality of services received, and the extent to which these services had succeeded in helping them to stop the violence, access permanent shelter, economic opportunities and resources, resolve claims on family assets, or improve overall wellbeing. It also presents, from the service providers' side, the services offered by them and challenges they faced in providing quality services.

\section{Do Kadam Barabari Ki Ore}

We conducted repeated surveys with women who accessed the services of the helpline in two districts of the state; two surveys-an initial and a follow-up survey-were conducted among ever married women aged 18-49 who had sought the services of the helpline during March 2014 and August 2015. The first interview took place at the time of their initial visit to the helpline, that is after they had registered their complaint, or in the subsequent month before any intervention services were initiated. We interviewed a total of 200 women in the first interview. The follow-up interview was conducted approximately four months after the first interview so as to assess women's experiences at the helpline, and outcomes if any, in the intervening period; of the 200 women interviewed in the first interview, 169 women were interviewed during the follow-up visit.

We also conducted in-depth interviews with nine service providers of the helpline in six districts of the state.

\section{Distress conditions in which women sought helpline services}

All the women who contacted the helpline had suffered domestic violence in the course of their married life, with 91 percent of the women reporting lifetime experience of emotional violence, 86 percent reporting physical violence and 70 percent reporting sexual violence within marriage. Marital violence had persisted, moreover, in the month preceding the woman's first interview. While husbands were clearly more likely to perpetrate violence against women than were other family member/s, other members of the husband's family also inflicted violence on women (Figure 1).

Also notable is that almost four in five women had tolerated violence for considerable periods of time prior to seeking help. Indeed, of those reporting physical violence, 78 percent had first experienced the violence more than a year ago, and almost one-half (46\%) had their first such experience five or more years ago.

The helpline service providers agreed that the women sought the services of the helpline mainly because of emotional, physical and/or sexual violence. They corroborated women's reports of tolerating violence for several years prior to seeking helpline services.

Most of them (women) come due to domestic violence and others come for help because they had a fight with their husband..... They come here because everything here is free of cost.... (Women come to us) mostly because of physical violence done on them in their home or in a public place; very few come because the husband has threatened to take his wife's life..... Very rarely, we get cases of sexual abuse, maybe one or two cases in a year..... [Helpline, ID-6]

Figure 1: Women's experience of violence perpetrated by their husband and other marital family members

Violence perpetrated by the husband

Violence perpetrated by other family member $/ \mathrm{s}^{*}$

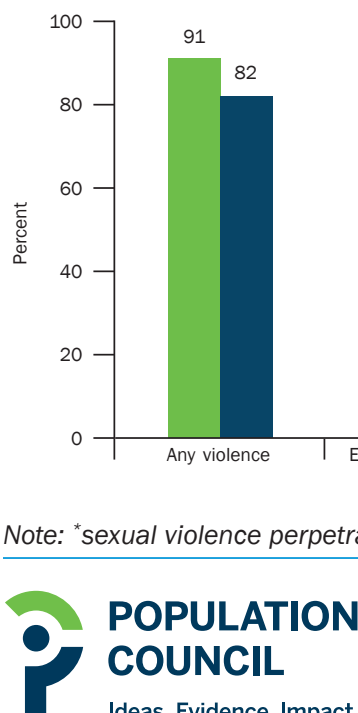

91
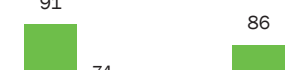

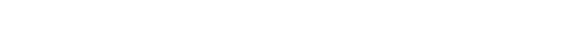

$89 \quad 89$

Ideas. Evidence. Impact

- In the month preceding the first interview

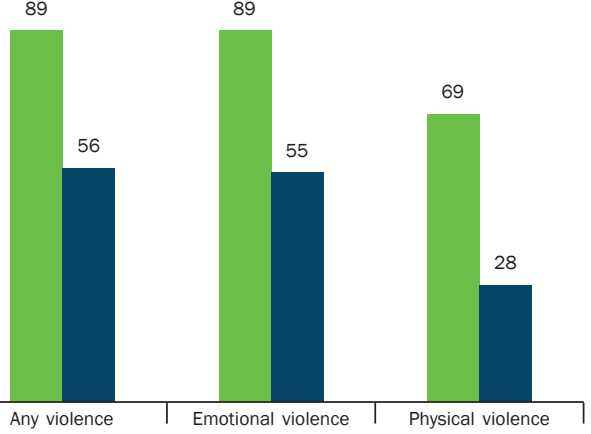

Ever

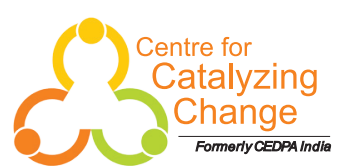

LONDON SCHOOL of HYGIENE \&TROPICAL MEDICINE 


\section{Reasons for delays in seeking helpline services}

A host of reasons held women back from approaching a helpline for assistance. The majority of women believed that the violence they had experienced was not 'severe' enough to warrant outside intervention, that seeking help would tarnish the family's honour, and enduring domestic violence was a women's lot. A considerable proportion of women feared repercussions for their children once family members became aware of their help-seeking effort. At the same time, large proportions of women reported lack of awareness about the helpline and its location and how to access it (Figure 2).

\section{Figure 2: Reasons for delays in seeking helpline} services

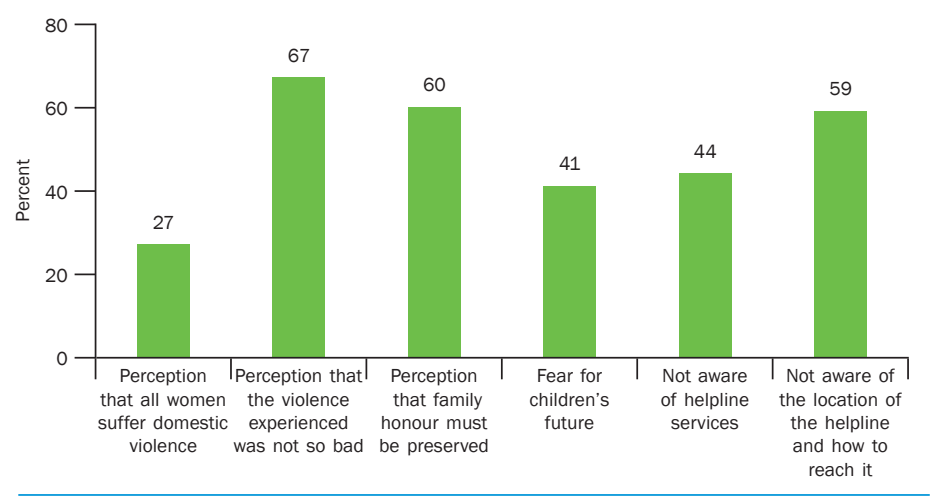

Helpline service providers attributed women's delay in seeking helpline services to women's reluctance to communicate with others about the violence, their limited freedom of movement outside the home, their fear that seeking help will result in increased violence, and their general lack of knowledge about the existence of support services such as the helpline.

It is very difficult for them (women) to get out of the house; ....still, somehow they reveal their problem to their mother or brother..... who pass on the message to us. The biggest hurdle is that they can't come on their own to this place (helpline) as they are not allowed to leave the house and even if they want to pass any message to us (through someone), other people their husband or in-laws - try to stop that piece of information from reaching us..... [Helpline, ID-3]

\section{Trajectory of receiving services from the helpline}

Almost all the women had made their first contact through a personal visit to the helpline; just nine percent had made a telephone call before the first visit. The first meeting was typically short, lasting less than ten minutes, on average, and focused on completing the registration formalities and providing a brief history of their experiences for preparing a case file. As most women had approached the helpline with the intention of forging a reconciliation with their husband or family members, over four-fifths of women reported that the Counsellor had promised to work towards a reconciliation, with more than three-quarters of all women reporting that the Counsellor had informed them that a joint meeting would be called with the person/s who had perpetrated violence on them. In just two cases, women reported that they had been advised separation or temporary shelter in a short stay home.

Between the time of the first and follow-up interviews, almost all women interviewed at follow-up reported some contact with the helpline. Specifically, 42 percent had telephoned the helpline at least once, 86 percent had visited it at least once, and $5 \%$ had received a home visit from a helpline Counsellor at least once. Many of those who had visited the helpline had done so along with their perpetrators in order to seek reconciliation.

The follow-up consultation at the helpline typically took at least 15 minutes, and 42 percent reported that it took half an hour or longer. During this consultation, the helpline Counsellor had reassured them that the helpline was working towards reconciliation or maintenance or was in the process of arranging a joint reconciliation meeting (in $71 \%$ of cases). Few women-12 percent-were informed about the linkages the helpline had with the police, legal aid and shelters. Some 15 percent of women reported that the Counsellor had informed them that the helpline would be unable to address the woman's case if her husband or family perpetrator/s did not attend the joint meeting called by the helpline, 10 percent reported that the Counsellor had recommended that the woman adjust to her family situation, and two percent each reported that the Counsellor told them that they would not intervene in cases of property disputes or if cases were already in court. Finally, among women who had requested assistance from the helpline in acquiring economic support or assets, the helpline had arranged for them to obtain economic support (28\%), had helped them to identify assets to which they were entitled (21\%), or had succeeded in or were in the process of helping them to access these assets (35\%).

Helpline service providers explained that their services focused on providing counselling to women and their perpetrators and arriving at a reconciliation between husband and wife; links with the police and the law were made relatively rarely, for those for whom reconciliation was not possible, those who wanted a divorce or child custody, and those who were severely injured.

\section{Quality of services received}

Women's first contact with the helpline was overwhelmingly positive. By the time of the follow-up interview too, women generally rated the quality of services positively. They were treated respectfully and made to feel comfortable, and the duration of the consultation was not rushed. At both times however, women mentioned the lack of visual and auditory privacy in their consultation with the Counsellor, no doubt the result of the space constraints faced by helplines. Some follow-up responses suggested some level of dissatisfaction with helpline services: long waiting time to meet the Counsellor; helpline staff members had talked to them indifferently at least once for not complying with helpline instructions or recommendations, or for not attending helpline appointments (Figure 3).

Figure 3: Quality of interactions with the helpline staff during women's first and follow-up interactions

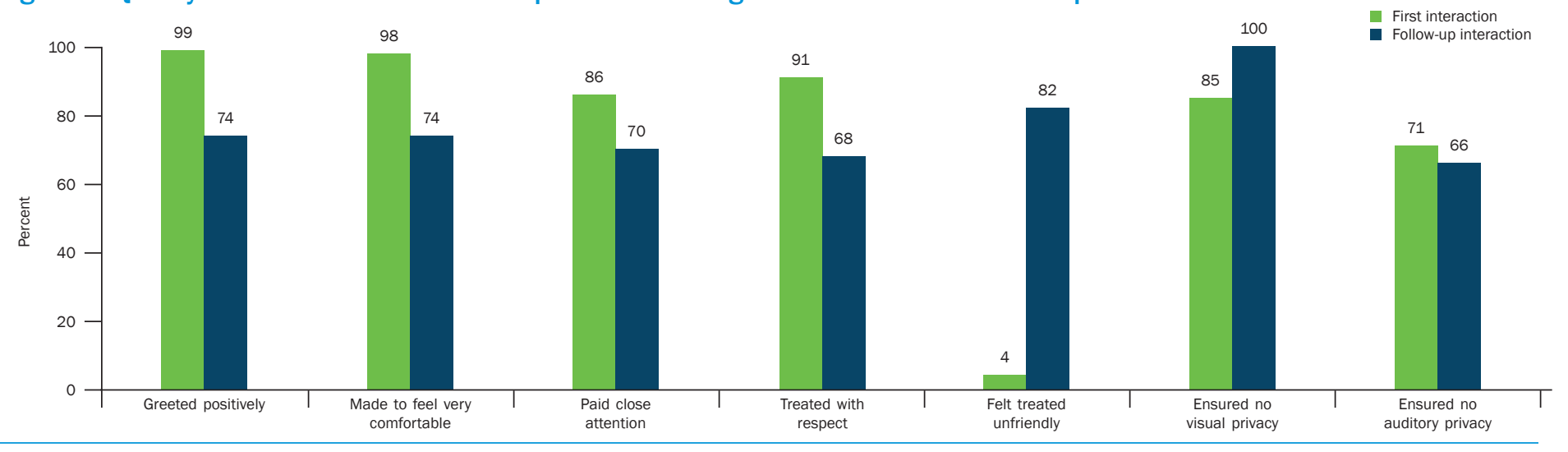




\section{Acceptability of helpline services}

The majority of women found helpline services acceptable; over onehalf of the women suggested that they would use helpline services again if the need arose. Just five percent reported that they would not use the services again. Some 40 percent of women were unsure about using the helpline services (Figure 4).

\section{Figure 4: Acceptability of helpline services}

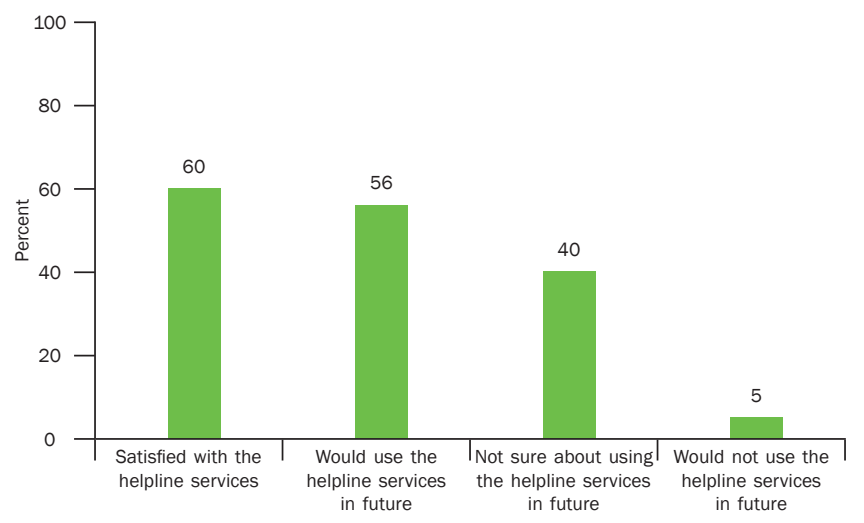

\section{Effectiveness of helpline services}

Women's assessments of the effectiveness of helpline intervention were mixed. While 51 percent reported that they had indeed received support in terms of achieving a reconciliation, securing maintenance or filing their case in a court, the remaining half reported that helpline intervention had not yet succeeded, within the four months following their first visit, in reducing or stopping the domestic violence against them or in satisfactorily resolving their problem.

Effectiveness of helpline services, as measured by women's reports of violence, husband's alcohol abuse, residential arrangements and suicidal ideation at first and follow-up interviews, was also mixed (Figure 5). Significant declines were observed in women's experience of physical violence perpetrated by the husband and other family member/s, sexual violence perpetrated by the husband, co-residence with husband and suicidal ideation. However, no changes were observed in women's experience of emotional violence and husband's alcohol abuse.

While most women reported no change in their economic security, almost one-quarter felt that it had improved and many of these women attributed the improvement to the intervention of the helpline. Between one-third and two-fifths of women reported that they were better off after seeking help from the helpline: 41 percent were happier, 34 percent reported improvement in their health, 31 percent were better able to care for their family, and 36 percent each were more confident about dealing with day-to-day matters, and had more peace of mind.
Helpline service providers were far more likely than women themselves to suggest a successful resolution of conflicts brought to the helpline. They suggested, for example, that 80 percent or more cases were successfully resolved, and to accomplish this, they typically required more than one joint meeting between the woman and her husband and/or family member/s, with the helpline service provider playing the role of observer and mediator. Even after a reconciliation has been forged, helpline service providers continue to follow the woman up to ensure her wellbeing and that her husband and/or family member/s had remained faithful to the conditions of the agreement to which they had committed. Most helpline service providers agreed that the typical case is resolved within three months; those requiring police or legal engagement take longer.

\section{Challenges faced by helpline service providers}

The helpline service providers narrated several challenges they faced in providing services to women in distress. Key were their need for training and the dearth of staff, financial resources and space to conduct their work. For example, while helpline service providers reported that they underwent training at regular intervals that focused on counselling needs, they believed that they needed to be better oriented about laws and their implementation.

Yes, it was useful but I think I need more training and more thorough training because issues like law and domestic violence are very vast and important and one or two training programmes are not enough. It is obvious that the training is incomplete when you don't know about the (DV) Act, about what it says about protection, residential rights, maintenance rights etc. We need to understand and we should know these things so that we can act according to the set of rules as suggested by the law; so, for this, we need to get more comprehensive training. A new set of laws has been introduced, for example, on eve teasing and when the Nirbhaya (gang rape) case happened in Delhi; training should have incorporated all this... [Helpline, ID-2]

A second concern was the dearth of staff; helpline providers suggested that the workload in the facilities prevented them from making home visits and following up with women whose cases had been resolved.

Finally, helpline service providers suggested that resources were not available to them to make home visits and so on, and that the lack of space in helpline premises inhibited confidential counselling.

\section{Recommendations}

Several lessons can be drawn from the experiences of women who sought the services of helplines and service providers of helplines that may inform the delivery of services for women in distress, and are relevant for improving the quality of services provided at helplines.

Figure 5: Changes in women's experiences of violence, husband's alcohol abuse patterns, residential arrangements and suicidal ideation at first and follow-up interview

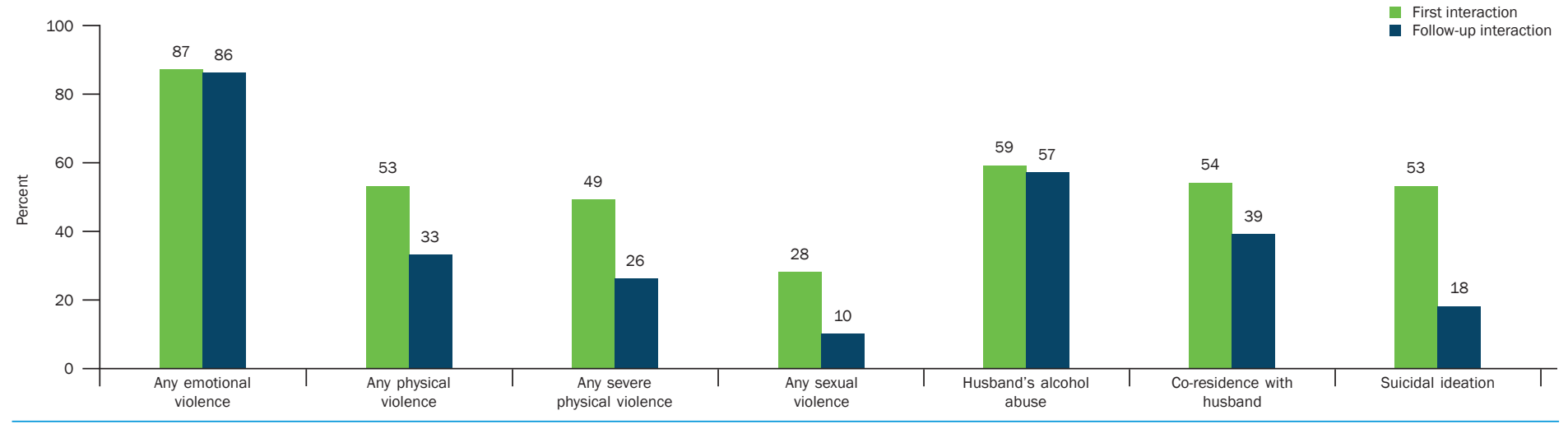




\section{Address infrastructural lacunae}

Both women and service providers identified a number of infrastructural lacunae: lengthy waiting periods, and lack of auditory and visual privacy. Observation at helpline facilities confirms that the client load is significant and counsellors may be unable to provide sufficient time to each client, let alone provide follow-up services after the case is resolved. Efforts need to be made to resolve these issues.

\section{Raise community awareness about the availability of services}

Findings have underscored the limited awareness among women about the availability of the helpline. Lack of awareness was a significant reason for delays in seeking help. Efforts must be made to spread awareness about these facilities and the services they offer through leaflets, posters and banners, as well as in the course of Panchayat, self-help group and other group meetings. Information should encompass the telephone number and location of the facility, as well as the facts that services are free of charge and linkages are made with the police, medical care and the legal system if required.

\section{Ensure quality care in helplines}

Findings suggest that counselling focused almost entirely on arriving at a reconciliation between the woman and her husband and other family members. Undoubtedly, this was also what women themselves preferred; yet, during counselling, it would be useful to offer women all options, and suggest that in some instances reconciliation is not accepted by the perpetrating party or is not in the woman's best interest. As a result of the focus on reconciliation, few women were informed about the helpline's linkages with other services, or were told that the helpline could facilitate meetings between women and the legal system. Some suggested that home visits were essential even after a case had officially been resolved. Finally, some women who were followed up reported that helpline staff had treated them indifferently. Undoubtedly, these quality of care limitations are linked, in large part, to the paucity of counsellors and of the time they could spend with each help seeker; nevertheless counsellors must be apprised of certain minimal issues that are non-negotiable: quality of interaction with women seeking help; information about the range of options available to women, including but not restricted to reconciliation efforts; and the helpline's ability to facilitate linkages to the police, medical care and the legal system, and make home visits where appropriate.

\section{Strengthen follow up of resolved cases}

Follow up of women who have passed through the helpline is essential to ensure that violence does not recur; it is unrealistic to believe that in a setting in which violence is the norm, the engagement with the helpline is sufficient to deter husbands or family members from engaging in violence even after a settlement is reached. Findings underscore the need for regular interaction between helpline service providers and women who had availed of their services for at least six months following the resolution of individual cases.

\section{Link women to community groups, support opportunities}

Itisessentialto developcommunitygroupsassupportoutpostsforwomen who have experienced violence and are in need of helpline services or shelter to access support services on the one hand, and those who cases have been resolved to re-settle in their marital home, on the other. Self-help groups and Panchayats need to be sensitised about the unjustifiability of violence against women, and oriented about how to intervene, about referring women to helplines, and helping those whose cases have been resolved to readjust and ensure that the terms of their agreement with their husband and/or other family members are not violated.

\section{Facilitate economic self-reliance among women}

The need for economic self-reliance among women who have sought helpline services was acknowledged by both women who sought such help as well as the service providers. Efforts are needed that recognise the need of women in distress for some form of economic support, and to reinstate the policy of providing women small seed funding with which to start a business or build an existing one.

\section{Acknowledgements}

We are extremely grateful to colleagues from the Women Development Corporation, Bihar - Rupesh Kumar Sinha, Project Director, Ratan Kumar, Senior Programme Officer, and Pramila Kumari, Project Manager cum Protection Officer, Patna Helpline, for their valuable support throughout the study. The authors would also like to gratefully acknowledge insightful comments that Madhuri Das, Ann Blanc, Mamta Kohli and Nel Druce made on earlier versions of this brief; Komal Saxena helped in the design and production of this brief. The authors also gratefully acknowledge the financial support provided by the UK Department for International Development (DFID).

Suggested citation: Santhya, K. G. and S. J. Jejeebhoy. 2017. Acceptability and effectiveness of helpline services: Perspectives of women in distress and service providers, Policy Brief. New Delhi: Population Council.

\section{Population Council}

Zone 5A, Ground Floor

India Habitat Centre, Lodi Road

New Delhi, India 110003

Phone: +91-11-2464 2901

Email: info.india@popcouncil.org

The study has been funded by UK aid from the UK Government; however the views expressed do not necessarily reflect the UK Government's official policies.

\section{POPULATION COUNCIL}

Ideas. Evidence. Impact.
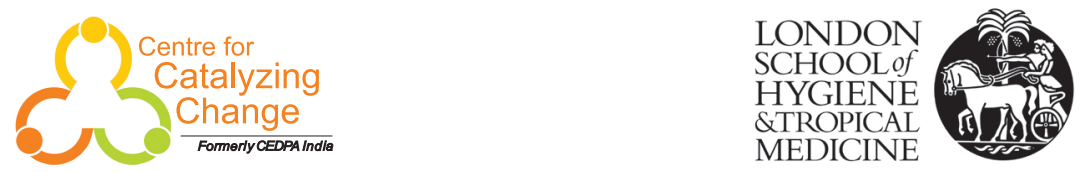

The Population Council conducts research and delivers solutions that improve lives around the world. Big ideas supported by evidence: It's our model for global change. www.popcouncil.org

() 2017 The Population Council, Inc. 